\title{
O PROCESSO DE APRENDIZAGEM EM REDES HORIZONTAIS DO ELO VAREJISTA DO AGRONEGÓCIO: UMA ANÁLISE SOB A PERSPECTIVA DAS ESTRATÉGIAS, DOS MÉTODOS E DOS ESTÁGIOS EVOLUTIVOS
}

\author{
Vânia de Fátima Barros Estivalete \\ vaniafbe@terra.com.br \\ Universidade Federal de Santa Maria - Santa Maria, RS / Brasil \\ Eugênio Ávila Pedrozo \\ eapedrozo@ea.ufrgs.br \\ Universidade Federal do Rio Grande do Sul - Porto Alegre, RS / Brasil \\ Heron Sérgio Moreira Begnis \\ heron@unisc.br \\ Universidade de Santa Cruz do Sul - Santa Cruz, RS / Brasil
}

\begin{abstract}
Recebido em 08/07/2009
Aprovado em 03/11/2010

Disponibilizado em 01/04/2012

Avaliado pelo sistema double blind review

Revista Eletrônica de Administração

Editor: Luís Felipe Nascimento

ISSN 1413-2311 (versão on-line)

Editada pela Escola de Administração da Universidade Federal do Rio Grande do Sul.

Periodicidade: Quadrimestral
\end{abstract}

Sistema requerido: Adobe Acrobat Reader.

\section{RESUMO}

Esta pesquisa tem como foco o estudo da aprendizagem em duas redes horizontais, do ramo gaúcho de supermercados. Estas redes fazem parte do elo do varejo do segmento do agronegócio, o qual exerce um papel dominante na definição das escolhas das atividades das demais empresas e fornecedores (elos) que participam dos relacionamentos interorganizacionais. Assim, os objetivos deste trabalho consistem em: (i) identificar as estratégias individuais de aprendizagem adotadas pelas organizações que participam das redes horizontais analisadas; (ii) identificar como as empresas inseridas em redes horizontais aprendem (método de aprendizagem) e; (iii) verificar em que estágio evolutivo de aprendizagem interorganizacional as empresas se encontram. A presente pesquisa caracterizase por ser de natureza qualitativa e exploratória e o método adotado é o do estudo de casos múltiplos. A coleta dos dados ocorreu através de questionários, entrevistas, análise documental e histórias de aprendizagem. Os resultados revelaram que existe diferença entre as estratégias, os métodos e os estágios evolutivos de aprendizagem interorganizacional adotados pelas empresas pertencentes às duas redes estudadas e estas podem ser decorrentes da participação de um coordenador externo e da existência de um planejamento conjunto das ações e atitudes desenvolvidas. Na rede que conta com a presença de um coordenador externo identificou-se um comportamento estratégico voltado à colaboração, o método de aprendizagem utilizado é o interativo e o estágio evolutivo caracteriza-se como sendo de re- 
O processo de aprendizagem em redes horizontais do elo varejista do agronegócio: uma análise sob a perspectiva das estratégias, dos métodos e dos estágios evolutivos

orientação. Na rede onde não há a presença de um coordenador externo constatou-se comportamentos estratégicos voltados à evitação e, compromisso em direção à competição, os métodos de aprendizagem utilizados são aprendizagem ativa e passiva e o estágio evolutivo é o de convergência.

Palavras-Chave: aprendizagem, redes horizontais, relacionamentos interorganizacionais, agronegócio, estratégias de aprendizagem.

\title{
THE LEARNING PROCESS IN HORIZONTAL NETWORKS OF THE AGRIBUSINESS RETAIL CHAIN: AN ANALYSIS FROM THE STRATEGIES, METHODS AND EVOLUTIVE STAGES PERSPECTIVE
}

\begin{abstract}
This research has as focus the study of the learning in two horizontal networks in to agribusiness retail segment. This link plays a dominant role in the process that defines the choices of the other companies and suppliers (other links) that participate in these interorganizacional relationships. In this way, the objectives of this article are: (i) to identify the individual learning strategies adopted by the organizations that participate in the analyzed horizontal networks; (ii) to identify how the companies in the horizontal networks learn (the learning method) and; (iii) to verify in which evolutionary status of interorganizacional learning the researched companies are. This research is characterized as qualitative and exploratory nature and the adopted method is the multiple cases study. The results revealed the existence of differences among the strategies, the methods and the evolutionary status of interorganizacional learning adopted by the companies in the studied networks. These differences can be derived from participation of an external coordinator and of the existence of a joined actions and attitudes planning process. In the net where there is an external coordinator we can identify a collaborative behavior. The interactive learning method is used in this net and the evolutionary stage is characterized as re-orientation. In the net where has not an external coordinator we identify a strategic behavior that leads to avoidance and commitment that leads to competition. The learning methods used in this net are active learning and passive learning and the evolutionary stage is characterized as convergent.
\end{abstract}

Keywords: learning, horizontal networks, interorganizacional relationships, agribusiness, learning strategies.

\section{Introdução}

Este início de século está sendo marcado por diversas características peculiares apresentando novos desafios e oportunidades para as organizações. Assim, a necessidade de mudança tornou-se necessária, em função da ruptura do paradigma cartesiano, que apregoa a idéia de fragmentação e reducionismo para compreensão dos fenômenos organizacionais (FERNANDES, 2002). Para enfrentar os desafios demandados por este contexto de mudanças, Fernandes (2002) comenta que os pesquisadores têm buscado outros alicerces que 
vislumbrem uma maneira diferenciada de entender as conexões complexas que estes fenômenos têm imposto às organizações. Um destes alicerces está calcado no processo de aprendizagem como estratégia eficaz para implementação e manutenção das mudanças organizacionais. Isto ocorre, principalmente, pelo fato de que uma das novas tendências que vêm se solidificando no campo dos estudos organizacionais são as formas de relações interorganizacionais, como, por exemplo, a formação de redes de empresas (AMATO NETO, 2000).

Em se tratando de arranjos interorganizacionais como redes de empresas, entende-se como relevante o processo de aprendizagem interorganizacional, visto que as organizações que estabelecem relacionamentos em rede poderiam não ter acesso ao conhecimento, se não existissem interações entre as organizações individuais e suas parceiras. Segundo o entendimento de Mohr e Sengupta (2002), a aprendizagem nas relações interorganizacionais repousa em um paradoxo. De um lado, alguns teóricos consideram a aprendizagem interorganizacional como uma extensão da aprendizagem organizacional, desenvolvendo uma base de conhecimento que pode apresentar reais oportunidades e prover novos insights para a implementação de estratégias e para a conquista de novos mercados (MOHR e SENGUPTA, 2002). Por outro lado, Mohr e Sengupta (2002) mencionam que a aprendizagem interorganizacional pode conduzir à transferência não-intencional e indesejável de habilidades, resultando em uma diluição potencial de conhecimento, o que, por sua vez, forma a base da vantagem competitiva limitando a transparência e o compartilhamento de informações. A existência deste paradoxo requer estudos que possam orientar os gestores e acadêmicos na condução do processo de aprendizagem. Tais estudos podem contribuir para a sustentabilidade dos relacionamentos interorganizacionais de forma a maximizar os benefícios e minimizar os riscos subjacentes às relações colaborativas. Diante disto, emergiram as seguintes indagações que motivaram o desenvolvimento da pesquisa que originou este trabalho:

- Como as organizações que estabelecem relacionamentos horizontais em redes aprendem e se apropriam dos conhecimentos que transitam nas relações estabelecidas?

- As estratégias de aprendizagem interorganizacional adotadas pelas organizações que estabelecem relacionamentos horizontais em rede diferem em função das iniciativas para a formação das redes?

- Em que estágio evolutivo de aprendizagem as organizações inseridas em redes se encontram? 
O processo de aprendizagem em redes horizontais do elo varejista do agronegócio: uma análise sob a perspectiva das estratégias, dos métodos e dos estágios evolutivos

Este estudo tem seu foco de análise dirigido a duas redes do ramo de supermercados, que fazem parte do elo do varejo do segmento do agronegócio do Rio Grande do Sul e que exerce um papel dominante na definição das escolhas das atividades das demais empresas e fornecedores (elos) que participam dos relacionamentos interorganizacionais. Assim, este trabalho tem como objetivos:

1. Identificar as estratégias individuais de aprendizagem adotadas pelas organizações que participam das redes horizontais analisadas;

2. Identificar como as empresas inseridas nas redes analisadas aprendem (método de aprendizagem) e;

3. Verificar em que estágio evolutivo de aprendizagem interorganizacional as empresas se encontram.

Visando alcançar os objetivos propostos, realizou-se um estudo de caráter exploratório que, segundo a proposta de Malhotra (2001) tem como principal objetivo o fornecimento de critérios sobre a situação-problema enfrentada pelo pesquisador e sobre a sua compreensão.

Com base nestes objetivos, este artigo está estruturado em mais cinco seções, além da introdução. A segunda seção apresenta a temática da aprendizagem interorganizacional, centrando-se numa discussão sobre as estratégias de aprendizagem interorganizacional, os métodos para aprender novos conhecimentos e os estágios evolutivos de aprendizagem interorganizacional. Na terceira seção aborda-se a metodologia e os procedimentos utilizados para operacionalização da presente pesquisa. A quarta seção apresenta os resultados da pesquisa sendo abordada uma análise individualizada das redes estudadas. Por fim, são apresentadas as considerações finais e as referências que serviram de base para o estudo realizado.

\section{Aprendizagem Interorganizacional: Um Conceito Emergente}

Em relação à temática da aprendizagem, este estudo representa um avanço para o conhecimento acadêmico brasileiro, ao apresentar um olhar aprofundado e diferenciado para a análise deste fenômeno ao acrescentar o nível interorganizacional a esta análise, visto que, no Brasil, a grande maioria dos estudos realizados (RUAS, 2001; LOIOLA e BASTOS, 2003; ANTONELLO, 2004; KARAWEJCZYK, 2005) relacionam-se à aprendizagem nos níveis individual e organizacional.

A discussão envolvendo a aprendizagem interorganizacional tem se revelado como uma estratégia para o desenvolvimento de capacidades que minimizam a exposição das empresas às incertezas impostas pelo ambiente, considerando-a uma dimensão representativa 
no sucesso das organizações (LARSSON et al., 1998; DYER e SINGH, 1998; LANE e LUBATKIN, 1998).

A revisão da literatura aponta para discussões conceituais sobre o que realmente possa significar a aprendizagem interorganizacional e permitiu observar que existem várias denominações, dentre as quais destacam-se: aprendizagem interativa (LANE e LUBATKIN, 1998), aprendizagem recíproca (LUBATKIN, FLORIN e LANE, 2001), aprendizagem coletiva (LARSSON et al., 1998), aprendizagem interfirma (MOHR e SENGUPTA, 2002) e aprendizagem em rede (KNIGHT, 2002).

Uma corrente teórica muito utilizada e citada nos estudos sobre aprendizagem interorganizacional foi a desenvolvida por Cohen e Levinthal (1990, p. 128), que cunharam o termo capacidade absortiva, que significa "a habilidade de uma empresa para reconhecer o valor do novo conhecimento externo, assimilá-lo e aplicá-lo para fins comerciais". De uma maneira sucinta, Lane e Lubatkin (1998) postulam que a definição proposta por estes autores busca capturar os passos envolvidos em um processo de aprendizagem interorganizacional, já que foca na habilidade de uma empresa para valorizar, assimilar e utilizar um novo conhecimento. E este pode vir do ambiente, incluindo-se tanto os concorrentes quanto os relacionamentos interorganizacionais com os parceiros. Um dos métodos para aprender conhecimento novo, para Lane e Lubatkin (1998), é o da aprendizagem denominada interativa, a qual contribui para o desenvolvimento de capacidades singulares e valiosas, através da transferência e da aquisição de conhecimentos articuláveis (observáveis) e também tácitos.

Nesta mesma linha de pensamento, o estudo de Lubatkin, Florin e Lane (2001) apresenta os processos envolvidos em aprendizagem interorganizacional, denominada por eles de aprendizagem recíproca. Para estes autores, as pesquisas em alianças geralmente apresentam o objetivo de absorver ou adquirir o conhecimento dos parceiros para desenvolver sua própria competência dentro de um determinado setor, estando, muitas vezes, distantes de conhecer o processo de aprendizagem recíproca.

Outra corrente teórica envolvendo esta temática é a desenvolvida por Larsson et al. (1998), cuja compreensão atual da aprendizagem interorganizacional, denominada coletiva, foca, basicamente, como as organizações individuais podem ser consideradas um bom parceiro ou como tentam ganhar a corrida da aprendizagem. Larsson et al. (1998) postulam que o dilema da aprendizagem interorganizacional reside nos fatos de que: (a) sendo um bom parceiro, a organização passa a explorar um conhecimento existente através dos outros parceiros, tentando maximizar a apropriação individual da aprendizagem conjunta, e (b) tais 
O processo de aprendizagem em redes horizontais do elo varejista do agronegócio: uma análise sob a perspectiva das estratégias, dos métodos e dos estágios evolutivos

estratégias de aprendizagem oportunista impedem o desenvolvimento do conhecimento coletivo na aliança estratégica.

Outra discussão que se faz presente na literatura sobre aprendizagem interorganizacional é abordada por Mohr e Sengupta (2002), ao mencionarem que a aprendizagem interorganizacional, por eles denominada como aprendizagem interfirma, pode aumentar a posição competitiva das partes envolvidas, como também pode conduzir à perda de habilidades e à diluição do conhecimento, que juntamente formam a base da vantagem competitiva. Isto pode ocorrer, segundo estes autores, quando existirem assimetrias no processo de aprendizagem entre as empresas parceiras, resultando em distribuição desigual de riscos e benefícios na relação colaborativa.

Com base no exposto, acrescenta-se a este panorama a contribuição de Knight (2002), ao apresentar o conceito de aprendizagem em rede. De acordo com Knight (2002), esta aprendizagem seria mais do que a soma das aprendizagens dos indivíduos, grupos e organizações que constituem a rede. Se, por meio de suas interações, um grupo de empresas mudar o seu comportamento ou as suas estruturas cognitivas, então, o aprendiz é o grupo de organizações, e não somente as organizações individuais dentro do grupo. Em tal situação, pode-se dizer que as organizações e a rede é que aprenderam (KNIGHT, 2002).

Para Huang e Chu (2010) a aprendizagem interorganizacional denomina-se aprendizagem interativa e consiste na aquisição de novos conhecimentos através da interação entre os parceiros cooperativos.

Peters et al. (2010) compartilham do entendimento de que as empresas colaboram por várias razões, dentre as quais destaca-se a utilização do conhecimento coletivo para servir seus próprios clientes de modo mais efetivo, em um ambiente competitivo. Estes mesmos autores sinalizam para a necessidade de se ampliar às abordagens tradicionais para compreensão das redes, ao incluir a natureza e o propósito das interações entre os parceiros, assim como as características estruturais e o desenvolvimento do compartilhamento de significado e consenso entre os participantes da rede.

Como contribuições práticas, os estudos de Peters et al. (2010) apontam que as indústrias estão começando a colaborar com os competidores, tendo em vista a agregação de valor através da aprendizagem coletiva. Para Peters et al. (2010), a base de competição futura para muitas indústrias será através de comunidades de aprendizagem colaborativa.

O quadro teórico-conceitual apresentado remete a compreensão de que a temática aprendizagem interorganizacional merece ser aprofundada e, neste sentido, uma análise das estratégias de aprendizagem interorganizacional e dos métodos de aprendizagem adotados 
Vânia de Fátima Barros Estivalete, Eugênio Ávila Pedrozo \& Heron Sérgio Moreira Begnis

pelas organizações que estabelecem relacionamentos colaborativos, assim como a identificação do estágio evolutivo de aprendizagem em que as empresas se encontram pode resultar em um melhor entendimento de como ocorre a aprendizagem coletiva entre os parceiros envolvidos.

\subsection{Estratégias Individuais para a Aprendizagem Interorganizacional: Em Busca da} Ação Coletiva

Ao se tratar do tema da aprendizagem entre organizações, uma abordagem significativa é a apresentada por Larsson et al. (1998), que desenvolveram um framework para o entendimento do processo de aprendizagem coletiva em alianças empresariais. Este framework também avalia a forma como os resultados de aprendizagem conjunta são compartilhados entre as organizações envolvidas. Segundo Larsson et al. (1998), um dos principais dilemas envolvidos neste campo diz respeito à adoção de estratégias oportunistas, as quais podem impedir a produção do conhecimento coletivo nas alianças estratégicas.

O framework proposto por Larsson et al. (1998) procura ampliar a compreensão deste dilema dos comportamentos estratégicos orientados pelo oportunismo. É com referência no trabalho de Hamel (1991), que considera a combinação de dimensões de receptividade e de transparência e no modelo de conflito de comportamento de Thomas, que Larsson et al. (1998) formulam o seu framework. Como resultado, esses autores propõem uma tipologia (Figura 01), baseada na receptividade e na transparência de uma organização em relação a seus parceiros, que contempla cinco diferentes estratégias de aprendizagem: colaboração (altamente receptivo e altamente transparente); competição (altamente receptivo e não transparente); compromisso (moderadamente receptivo e transparente); acomodação (não receptivo e altamente transparente); evitação (não receptivo e não transparente). A tipologia de aprendizagem interorganizacional desenvolvida pelos autores é apresentada na Figura 01. 
O processo de aprendizagem em redes horizontais do elo varejista do agronegócio: uma análise sob a perspectiva das estratégias, dos métodos e dos estágios evolutivos

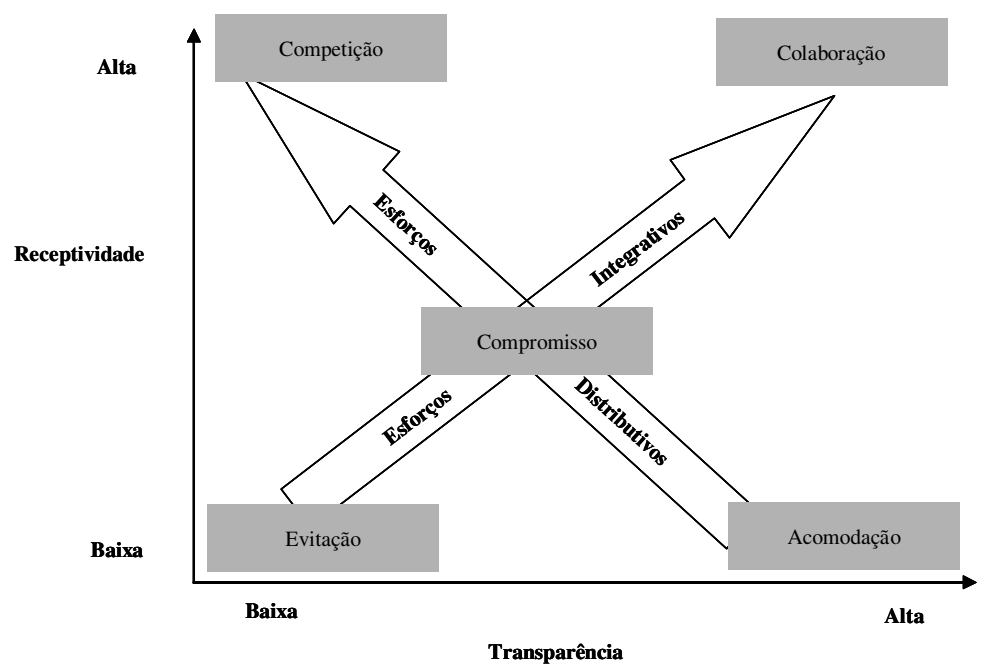

Figura 01 - Estratégias individuais para Aprendizagem Interorganizacional Fonte: Larsson et al. (1998, p. 289).

Para Larsson et al. (1998) as estratégias de colaboração e competição são altamente agressivas, visto que, para a absorção do conhecimento das empresas parceiras, apresentam alta receptividade. No entanto, esses dois tipos de comportamento estratégicos diferenciam-se em relação à transparência em descobrir conhecimentos das organizações parceiras que possuem relações de cooperação. Em oposição a essas duas estratégias (colaboração e competição), colocam-se as estratégias de evitação e de acomodação, as quais apresentam baixa receptividade para absorver os novos conhecimentos que transitam nos relacionamentos de parceria. Já a estratégia de compromisso mostra-se moderadamente receptiva e moderadamente transparente.

Conforme a interpretação de Larsson et al. (1998), a adoção de comportamnetos estratégicos caracterizados pela competição pode resultar em acréscimos no conhecimento das empresas parceiras que adotam um comportamento de alta transparência. Tal situação poderia fazer com que as outras organizações passassem também a empregar estratégias de competição. Nesse sentido, as combinações que envolvem estratégias de acomodação ou competitivas poderiam levar a resultados assimétricos em termos de aprendizagem interorganizacional, uma vez que se sobressai a dimensão individual de transferência e apropriação do novo conhecimento.

Segundo Larsson et al. (1998) as estratégias de evitação se caracterizam por apresentarem baixa transparência e receptividade na descoberta e na absorção de um novo conhecimento. Ao adotarem estas estratégias, as organizações podem dificultar ou eliminar a possibilidade de que ocorra uma significativa aprendizagem interorganizacional. Por outro lado, quando as organizações adotam comportamentos estratégicos direcionados à 
colaboração, essas estratégias permitem que, através dos relacionamentos e interações entre as empresas parceiras, a maximização conjunta de resultados seja potencializada, principalmente em termos de transparência mútua e criação de novos conhecimentos (LARSSON et al., 1998).

\subsection{Métodos e Estágios Evolutivos de Aprendizagem Interorganizacional:}

\section{Compreendendo a Complexidade dos Relacionamentos}

Mais recentemente, tem sido amplamente reconhecida a importância dos relacionamentos interorganizacionais, apoiando ou impedindo o alcance dos objetivos das organizações (KNIGHT, 2002). Dentro de tal contexto, o processo de aprendizagem é considerado um elemento-chave, por oferecer o desenvolvimento de competências (LARSSON et al., 1998) e por desenvolver uma compreensão de como converter o conhecimento em capacidades que satisfaçam às demandas ambientais (LANE e LUBATKIN, 1998). Com base neste entendimento, acrescenta-se a concepção de Lane e Lubatkin (1998) ao reforçar que o conhecimento de uma empresa inclui um conhecimento articulável e facilmente comunicado, bem como um conhecimento tácito, não-codificado. Para estes autores, existem três métodos para aprender um novo conhecimento externo, conforme pode ser visualizado no Quadro 01, sendo que cada método fornece um tipo diferente de conhecimento.

Quadro 01 - Métodos de Aprendizagem e Tipos de Conhecimento

\begin{tabular}{|l|l|l|}
\hline Métodos & Conceituação & Tipo de Conhecimento \\
\hline Aprendizagem Passiva & $\begin{array}{l}\text { Ocorre quando as empresas } \\
\text { adquirem conhecimento } \\
\text { articulável sobre processos } \\
\text { gerenciais e técnicos através de } \\
\text { fontes como: jornais, seminários } \\
\text { e consultores. }\end{array}$ & $\begin{array}{l}\text { Conhecimento articulável } \\
\text { (observável), explícito (Nonaka e } \\
\text { Takeuchi (1994). }\end{array}$ \\
\hline Aprendizagem Ativa & $\begin{array}{l}\text { Fornecem uma visão mais } \\
\text { ampla das capacidades dos } \\
\text { competidores através de } \\
\text { benchmarking. }\end{array}$ & $\begin{array}{l}\text { Conhecimento articulável } \\
\text { (observável), explícito (Nonaka e } \\
\text { Takeuchi (1994). }\end{array}$ \\
\hline Aprendizagem Interativa & $\begin{array}{l}\text { Permite à empresa adicionar } \\
\text { valores únicos para suas } \\
\text { próprias capacidades através da } \\
\text { compreensão dos componentes } \\
\text { observáveis e tácitos do } \\
\text { conhecimento. }\end{array}$ & $\begin{array}{l}\text { Conhecimento } \\
\text { (observável), explícito (Nonaka e } \\
\text { Takeuchi (1994) e conhecimento } \\
\text { tácito. }\end{array}$ \\
\hline
\end{tabular}

Fonte: elaborado a partir de Lane e Lubatkin (1998)

De acordo com Lane e Lubatkin (1998), tanto a aprendizagem ativa como a passiva fornecem conhecimentos articuláveis (observáveis), o que significa dizer que estes conhecimentos não são raros, não são imperfeitamente comercializáveis e não são caros para 
O processo de aprendizagem em redes horizontais do elo varejista do agronegócio: uma análise sob a perspectiva das estratégias, dos métodos e dos estágios evolutivos

imitar. A transferência deste tipo de conhecimento, para estes autores, pode guiar o desenvolvimento de capacidades, mas não permite às organizações torná-los únicos, menos imitáveis ou com maior valor estratégico. Isto pode ser feito através da aprendizagem interativa, visto que as empresas desenvolvem habilidades para adquirir e compreender os componentes observáveis e tácitos do conhecimento que se encontram imbricados no contexto social das próprias empresas.

Dando seqüência a esta discussão, acrescenta-se o estudo de Lubatkin, Florin e Lane (2001). Estes autores destacam os processos envolvidos na aprendizagem interorganizacional, através do desenvolvimento de um modelo evolutivo no qual sucessivos ciclos de aprendizagem de convergência, divergência e re-orientação facilitam a criação do conhecimento entre empresas. O desenvolvimento do modelo, segundo estes autores, foi fundamentado em teorias da sociologia e da psicologia educacional, relacionadas à linha de pesquisa sobre aprendizagem cooperativa que foi desenvolvida por psicólogos sociais e educacionais (DYER e SINGH, 1998).

Para Lubatkin, Florin e Lane (2001), a aprendizagem cooperativa requer interdependência de recursos, de objetivos e de tarefas. A interdependência de recursos promove uma maior diversidade de perspectivas, e assim, facilita o alcance de um nível mais alto de aprendizagem grupal. Além disto, para os autores, também promove um senso de igualitarismo entre os participantes, facilitando que estes aprendam a apreciar o valor do conhecimento nas organizações envolvidas em relações de cooperação. A interdependência de objetivos faz com que os envolvidos percebam que podem atingir melhor os seus objetivos pessoais se trabalharem de modo cooperativo. Já a interdependência de tarefas possibilita uma melhor compreensão de que a agenda coletiva dos participantes é melhor realizada quando eles especializarem seus esforços para atividades às quais eles são individualmente mais competentes (LUBATKIN, FLORIN e LANE, 2001).

No desenvolvimento do modelo de aprendizagem recíproca interfirma, como mostra a Figura 02, Lubatkin, Florin e Lane (2001) identificaram tipos de conhecimento que são centrais para alianças recíprocas, estruturando-os em cinco fases ou estágios denominados: (a) know-what (domínio particular da informação, sua semântica - vocabulário, fatos, símbolos, etc. - e episódios - os vários tipos de desafios ou problemas encontrados no domínio da informação); (b) know-how (habilidade para articular ligações de causa e efeito); (c) knowabout (domínio informacional - áreas de expertise como a biotecnologia); (d) know-why (compreensão sobre os relacionamentos que possam conter restrições não-familiares ou nãoespecificadas e que sejam caracterizados como resposta de um competidor ou de um 
consumidor a uma resistência tecnológica); e (e) know-where (saber onde está armazenado o conhecimento de caráter tácito na empresa).

A Figura 02 apresenta os três estágios evolutivos de aprendizagem em alianças, caracterizados como estágios de convergência, divergência e re-orientação. De acordo com Lubatkin, Florin e Lane (2001), a convergência é o primeiro dos três processos evolutivos em que o processo de aprendizagem ocorre por reciprocidade de recursos e objetivos, representando um processo interativo por meio do qual as empresas parceiras simultaneamente aprendem a confiar e aprendem a aprender. Lubatkin, Florin e Lane (2001) advogam que através das atividades comuns repetidas, as empresas também podem desenvolver crenças compartilhadas e alavancar a interdependência de objetivos. E este último, por sua vez, também pode conduzir à co-aprendizagem e a descobertas conjuntas, o que as motiva a permanecer comprometidas com as normas de reciprocidade e as prepara para a próxima fase do processo de aprendizagem recíproca, que é o da divergência (LUBATKIN, FLORIN e LANE, 2001).

Na fase denominada divergência, Lubatkin, Florin e Lane (2001) mencionam que o processo de aprendizagem de empresas envolvidas em alianças de aprendizagem recíproca ocorre pela especialização através da interdependência de tarefas. Nesta fase, estes mesmos autores destacam que vários estrategistas reconheceram que as empresas podem aumentar a produtividade conjunta através da especialização cooperativa ou do investimento em recursos de transação específicos, os quais podem ser físicos, humanos e/ou processual. 
O processo de aprendizagem em redes horizontais do elo varejista do agronegócio: uma análise sob a perspectiva das estratégias, dos métodos e dos estágios evolutivos

\begin{tabular}{l}
$\begin{array}{l}\text { Condicionamento Prévio } \\
\text { Relativo }\end{array}$ \\
\hline
\end{tabular}

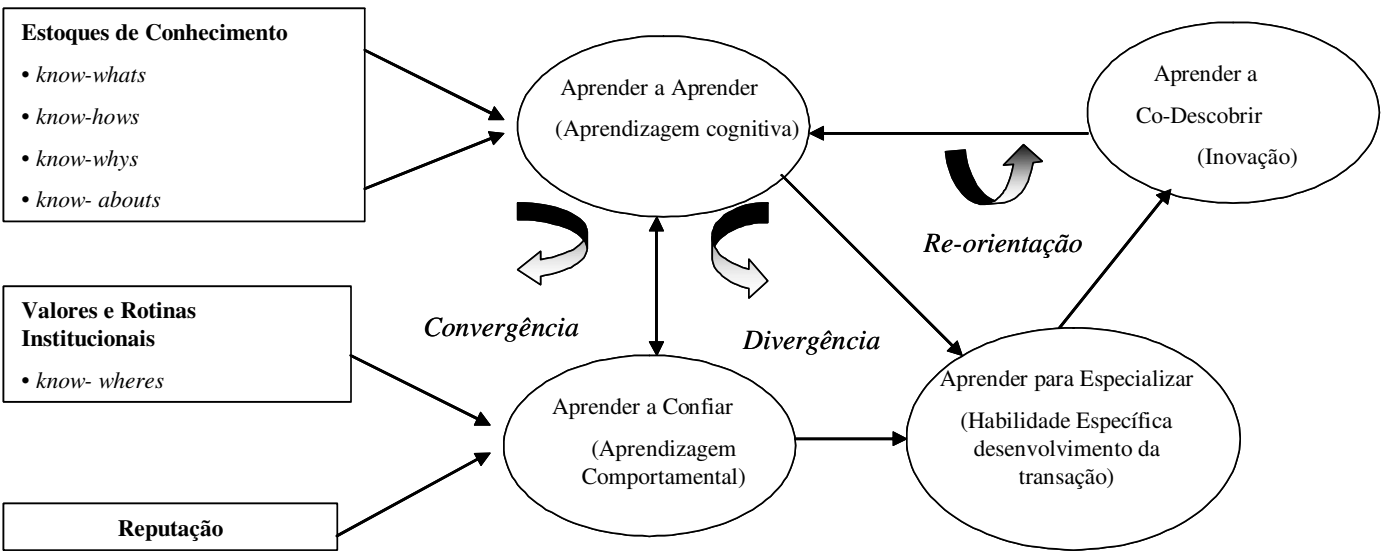

\footnotetext{
know-whats = semânticas e episódios

know-hows = ligações causa/efeito

know-whys = lógica de mercado

know- abouts = domínio informacional

Know-wheres $=$ institucionalização rotinas e valores
}

Figura 02 - Um modelo de aprendizagem recíproca interfirma Fonte: Lubatkin, Florin e Lane (2001, p. 1362).

Para Lubatkin, Florin e Lane (2001), o seqüenciamento de convergência para divergência é um processo co-evolutivo interativo. Ao assumir que o estoque de conhecimento das empresas parceiras é mutuamente complementar (condicionamento prévio relativo) o processo de convergência e sua série de ações em comum pode preceder a construção de confiança entre os atores envolvidos nos relacionamentos. Isto posto, Lubatkin, Florin e Lane (2001) ressaltam que a progressão para o estágio final de uma estrutura de conhecimento interfirma, denominado de re-orientação, pode não ocorrer se uma empresa deixar de agir de boa fé. Ou seja, segundo eles, este estágio envolve um processo dinâmico, não-linear e indutivo de descobertas comuns que são dependentes de fatores cognitivos, comportamentais e administrativos. Para estes mesmos autores, no estágio de re-orientação, a aprendizagem em alianças somente é possível na presença de três interdependências: recursos, objetivos e tarefas.

\section{Delineamento da Pesquisa e Método}

A presente pesquisa se caracteriza por ser de caráter qualitativo que, segundo Malhotra (2001), proporciona insights valiosos, que permitem alcançar uma compreensão qualitativa das razões e motivações subjacentes ao problema proposto. 
A estratégia de pesquisa pode ser classificada como exploratória, pois como o estudo da temática da aprendizagem interorganizacional é uma questão emergente no meio acadêmico, e ainda carece de trabalhos empíricos abordando o contexto brasileiro, entende-se que este estudo possibilita ampliar a compreensão e a familiaridade deste complexo fenômeno. E, deste modo, acredita-se que ele possa suscitar a motivação de outros pesquisadores para o desenvolvimento de novas pesquisas sobre este mesmo tema. Segundo a proposta de Gil (1999), os estudos exploratórios proporcionam uma maior flexibilidade na busca de informações sobre determinado problema, visando torná-lo mais claro, e possibilitando a construção de novas idéias sobre o tema abordado. Para melhor compreensão a Figura 03 apresenta uma síntese do modelo de pesquisa realizado neste estudo.

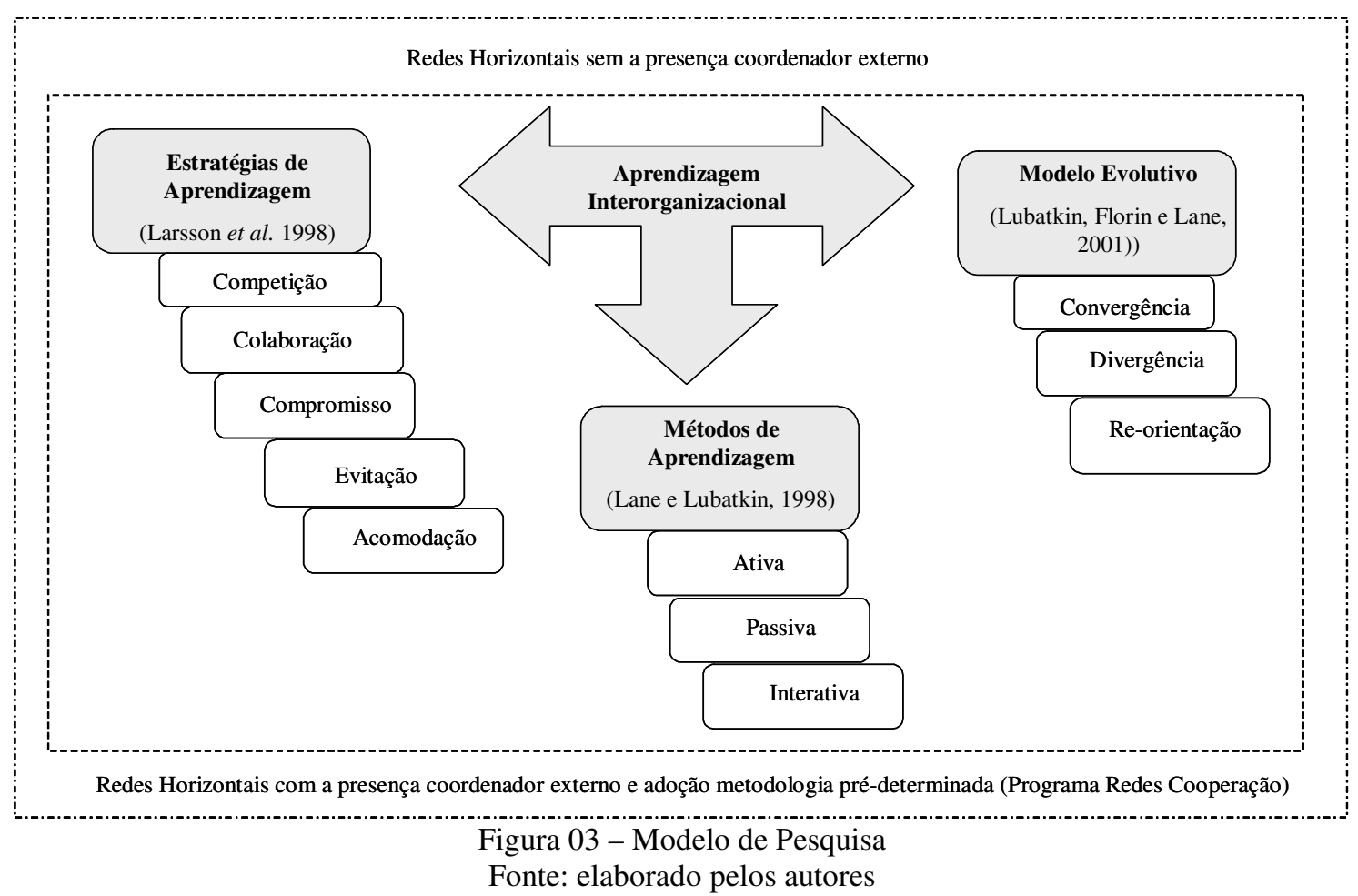

O método adotado para realização desta pesquisa é o do estudo de casos múltiplos (YIN, 2001), pois as unidades de análise são duas redes supermercadistas, que estabelecem relacionamentos horizontais, constituídas de pequenas e médias empresas que atuam no elo do varejo do segmento do agronegócio. Este método foi escolhido pelo fato de se mostrar alinhado com os questionamentos apresentados e com os objetivos propostos neste estudo. A escolha das redes estudadas foi feita de maneira intencional, a partir do interesse e da relevância do elo do varejo para o agronegócio de modo geral. O setor varejista é considerado um elo-chave na cadeia de produtos agroalimentares e exerce um papel importante e mesmo 
O processo de aprendizagem em redes horizontais do elo varejista do agronegócio: uma análise sob a perspectiva das estratégias, dos métodos e dos estágios evolutivos

dominante na definição das escolhas das atividades a serem desenvolvidas pela empresas (elos) que lhe fornecem seus produtos para comercialização. Uma das redes pesquisadas se formou a partir de iniciativas dos empresários, que se reuniram para estabelecer relações de cooperação sem a presença de um coordenador externo, denominada neste estudo de Rede Merca I. A outra rede também foi formada através de iniciativas dos empresários, no entanto, foi incentivada pelo Programa Redes de Cooperação do Governo do Estado do Rio Grande do Sul, com a presença de um coordenador externo e com a adoção de uma metodologia prédeterminada, denominada de Rede Merca II. A Rede Merca I é composta por 13 empresas, atuando em sete cidades, e a Rede Merca II é integrada por 17 empresas, que atuam em 10 cidades gaúchas.

Os entrevistados foram os gestores das organizações inseridas nas redes analisadas, perfazendo um total de 29 pessoas, sendo que 13 destes gestores atuam na Rede Merca I e os outros 16 gestores exercem suas atividades na Rede Merca II, destacando-se que um dos gestores desta rede possui dois supermercados que integram a rede. A coleta dos dados ocorreu em quatro etapas e as técnicas utilizadas foram centradas nas seguintes fontes de evidências: questionários, entrevistas individuais semi-estruturadas, fontes documentais e, na mesma linha dos estudos de Cabral (2001), também se utilizou outro instrumento de avaliação da aprendizagem, denominado histórias de aprendizagem.

Inicialmente, foi aplicado um questionário aos gestores investigados no sentido de identificar as estratégias adotadas em sua organização em relação à aprendizagem, desenvolvido com base nos estudos de Larsson et al. (1998). O questionário constou de questões fechadas envolvendo as dimensões de receptividade e transparência cujas alternativas variavam de alta, moderada ou baixa. Num segundo momento, foram realizadas entrevistas individuais em profundidade com todos os gestores, com duração aproximada de duas horas cada uma. Num terceiro momento, foram consultados documentos institucionais das duas redes estudadas, além de jornais internos, jornais externos, históricos das redes, folders institucionais com informações das redes e nomes das empresas que a integram e material de apresentação fornecido pelas redes investigadas. Por fim, inspirado nos estudos de Cabral (2001), utilizou-se a técnica histórias de aprendizagem. Nesta fase de coleta de dados, os gestores foram convidados a mencionar as mudanças ocorridas em suas empresas após a atuação na forma de redes, procurando ilustrar tais mudanças através de exemplos ou de situações que as caracterizassem, de modo prático. Vale ressaltar que o uso desta técnica serviu, basicamente, para complementar as demais, visto que a utilização de múltiplas fontes de dados pode proporcionar uma melhor compreensão do fenômeno que está sendo estudado. 
Na Figura 04 são apresentados, de modo detalhado, os instrumentos utilizados para a realização da pesquisa, sendo também descrita a forma pela qual os dados foram coletados e analisados.

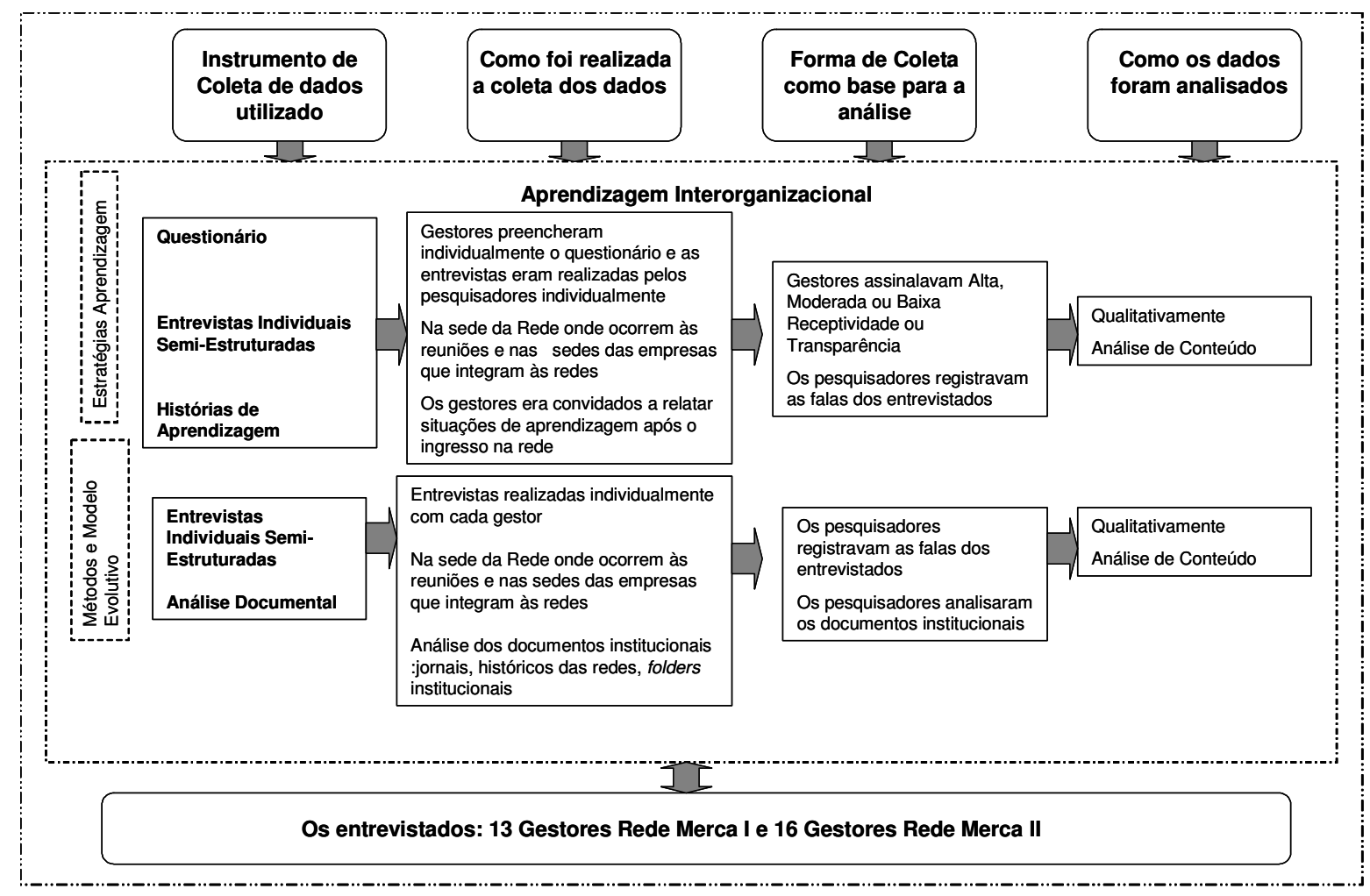

Figura 04- Detalhamento da Coleta dos Dados Fonte: Elaborado pelos autores

Neste estudo, foi utilizada a análise de conteúdo como estratégia de análise dos dados qualitativos da pesquisa.

\section{Análise Individualizada da Rede Merca I}

A Rede Merca I é formada, atualmente, por treze empresas varejistas do ramo de supermercados gaúchos, localizadas no interior do Estado do Rio Grande do Sul, localizadas em sete cidades gaúchas. A Rede Merca I foi fundada no ano de 1997 e foi originada através de iniciativas dos seus proprietários/associados, sem a presença de um coordenador externo. É composta de dois tipos de sócios: sócios denominados "fundadores" (responsáveis pela criação da rede) e sócios denominados "adesivos" (que passaram a participar da rede por adesão, ou seja, após a sua fundação). Os sócios adesivos não podem participar da diretoria, ou seja, não têm direito a voto, mas podem votar e participar das decisões coletivas que são tomadas pelas organizações participantes da rede. Dos treze sócios que compõem a rede, cinco são sócios fundadores e oito são sócios por adesão. 
O processo de aprendizagem em redes horizontais do elo varejista do agronegócio: uma análise sob a perspectiva das estratégias, dos métodos e dos estágios evolutivos

Segundo entrevistas realizadas com os gestores, ao Conselho Fiscal compete fiscalizar o cumprimento das determinações previstas no estatuto da rede. Ao Conselho de Administração compete a administração das receitas e despesas, promoções, ofertas e o mesmo também é encarregado da área financeira da rede. O Conselho de Ética se encarrega de ratificar o parecer final emitido pelo Conselho Fiscal.

Segundo entrevistas com os gestores, a rede tem desenvolvido as seguintes ações: compras conjuntas, realização de propagandas em rádios, TVs e encartes, e obtenção de maior crédito junto aos fornecedores. Considerando-se o conjunto das treze empresas que integram a Rede Merca I, foi verificado que o número de empregos diretos perfaz um total de, aproximadamente, 500 funcionários.

\subsection{Estratégias de Aprendizagem Interorganizacional adotadas pelas Organizações inseridas na Rede Merca I}

Realizando-se uma análise individual das organizações investigadas, pôde ser verificado que sete das organizações inseridas na Rede Merca I apresentam uma alta receptividade para absorver o conhecimento que é compartilhado através dos relacionamentos horizontais estabelecidos. Já em relação às receptividades baixa e moderada, foi constatado um equilíbrio no número de organizações, sendo que três dentre estas empresas revelaram possuir baixa receptividade, assim como três outras empresas manifestaram possuir receptividade moderada (ESTIVALETE, PEDROZO e BEGNIS, 2006). Em relação à transparência que, segundo Larsson et al. (1998), representa a cooperação em descobrir e compartilhar conhecimento entre as empresas parceiras, pôde ser constatado certo equilíbrio entre as avaliações de baixa (por gestores de cinco das empresas) e de moderada (pelos de outras cinco empresas) transparência na descoberta e disseminação de conhecimento. Apenas três empresas revelaram adotar uma estratégia de alta transparência em relação à aprendizagem conjunta. Analisando as dimensões de transparência e receptividade, de modo geral, pode-se inferir que as empresas pertencentes à Rede Merca I estão mais abertas para receber conhecimentos das empresas parceiras (receptividade) do que para disseminá-lo e compartilhá-lo (transparência).

A combinação entre estas duas dimensões - transparência e receptividade contempladas no modelo de Larsson et al. (1998), deu origem aos cinco tipos de comportamento estratégico mencionados anteriormente: evitação, acomodação, compromisso, competição e colaboração. A Figura 05 facilita a visualização desta observação, apresentando 
graficamente as estratégias de aprendizagem interorganizacional adotadas pelas empresas participantes desta rede de supermercados analisada.

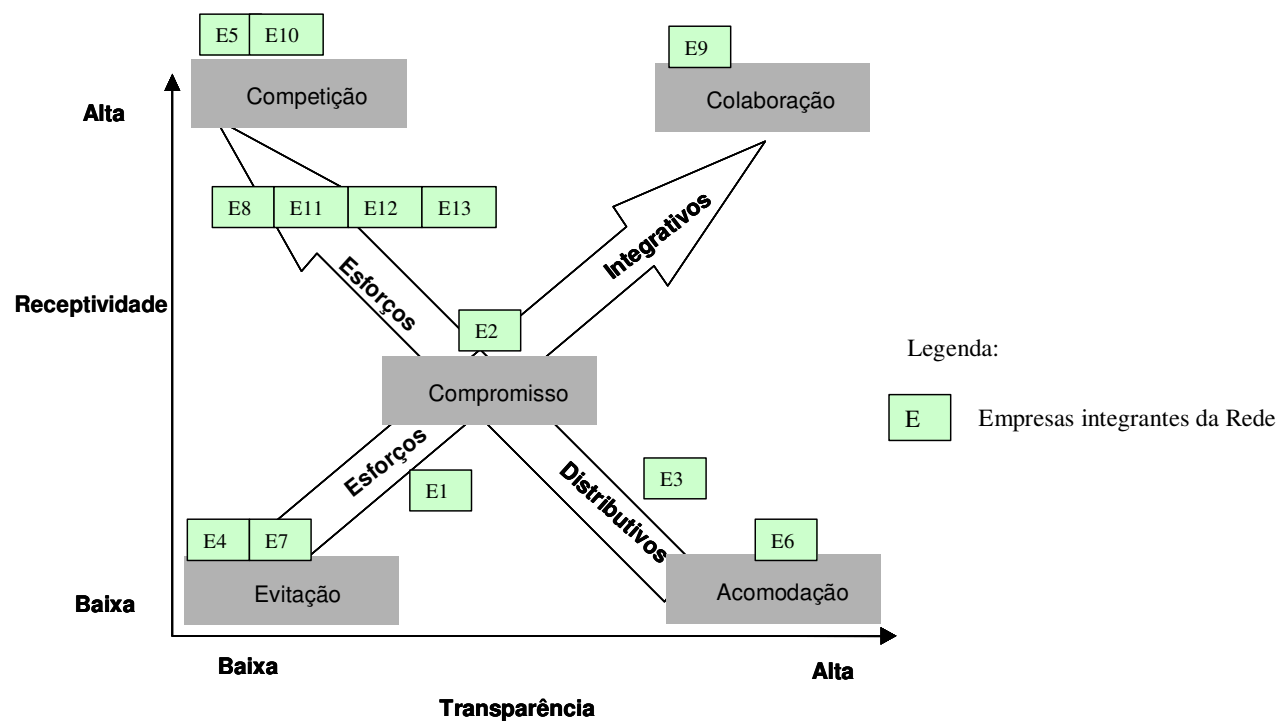

Figura 05- Estratégias de Aprendizagem Interorganizacional adotadas pelas Empresas da Rede Merca I Fonte: Adaptado de Larsson et al. (1998) de acordo com os dados da pesquisa.

As estratégias de aprendizagem interorganizacional, analisadas de modo conjunto, remetem ao entendimento de que a maioria das organizações investigadas está desenvolvendo esforços distributivos em relação à aprendizagem. E isto se revela através de alta e moderada receptividade nos relacionamentos horizontais estabelecidos e de baixa transparência no que se refere à descoberta e troca de conhecimentos. Na concepção de Larsson et al. (1998), este comportamento estratégico pode conduzir a resultados assimétricos em termos de aprendizagem, impedindo o desenvolvimento de conhecimento coletivo entre os atores envolvidos.

Nesta análise, como se observa na Figura 04, também pode ser destacada uma maior concentração em torno das estratégias de compromisso em direção à competição. Também está presente uma diversidade de comportamentos estratégicos, principalmente por parte das demais empresas, que aderiram à rede após a sua formação. As organizações inseridas no contexto da rede estudada devem estar atentas para a existência de comportamentos estratégicos voltados à evitação, uma vez que os mesmos podem eliminar e/ou impedir a possibilidade de que ocorra uma aprendizagem interorganizacional significativa em função da baixa transparência e receptividade em relação ao conhecimento que transita nas relações estabelecidas (ESTIVALETE, PEDROZO e BEGNIS, 2006).

De acordo com esta perspectiva, pode ser destacado que somente uma das empresas participantes da rede revelou adotar comportamento estratégico de colaboração, o que foi 
O processo de aprendizagem em redes horizontais do elo varejista do agronegócio: uma análise sob a perspectiva das estratégias, dos métodos e dos estágios evolutivos

manifestado através de alta receptividade e transparência em relação ao conhecimento descoberto e compartilhado. A adoção de estratégias de colaboração, como sustentam Larsson et al. (1998), conduz à maximização da aprendizagem interorganizacional, capacitando as organizações para a criação, descoberta e compartilhamento de conhecimento entre os envolvidos em relações de cooperação. Nesta lógica, com base no modelo de Larsson et al.,1998, os resultados conjuntos em termos de aprendizagem corresponderiam a esforços integrativos ao longo da diagonal principal de transparência e receptividade crescente. Assim, a tendência geral que se observa na Rede Merca I é a predominância de comportamentos que variam da estratégia de compromisso em direção à estratégia de competição e da estratégia de evitação entre as empresas analisadas.

\subsection{Métodos e Estágios Evolutivos de Aprendizagem Interorganizacional na Rede} Merca I

Ao analisar os métodos de aprendizagem e os tipos de conhecimento que são compartilhados na Rede Merca I, constatou-se que o conhecimento tácito quase não circula na rede, pois há o receio de que as organizações parceiras possam copiá-lo. Com base nos resultados, percebeu-se que o conhecimento explícito é o tipo de conhecimento que mais circula na rede, porém, na percepção de alguns dos gestores, não há clareza nas informações que são compartilhadas. Este aspecto merece destaque, pois, ao se tratar da aprendizagem em um contexto de relacionamentos interorganizacionais, devem ser consideradas as dimensões contempladas no conceito de capacidade absortiva, proposto por Cohen e Levinthal (1990). E esta avaliação é importante devido ao fato de que, primeiramente, é preciso que as organizações possam desenvolver as habilidades necessárias para reconhecer e assimilar o conhecimento externo. E, então, posteriormente, poder aplicá-lo. Para isto, torna-se necessária uma maior clareza e transparência nas informações que são compartilhadas entre os atores envolvidos.

Ao serem questionados sobre a forma como os gestores se apropriam de novos conhecimentos, os mesmos indicaram os seguintes aspectos: participação nas reuniões da rede, participação em cursos, palestras, feiras e seminários relacionados com o setor varejista, visitas às demais empresas e benchmarking. Com base nestas informações, foi constatado que as organizações participantes da Rede Merca I aprendem através dos métodos denominados aprendizagens passiva e ativa - segundo Lane e Lubatkin (1998) - na medida em que o conhecimento articulável (explícito) predomina nas relações estabelecidas e a aquisição do mesmo se dá através de diversas fontes. A transferência do conhecimento explícito e as 
diversas formas de apropriação do mesmo, na rede investigada, podem limitar e dificultar o desenvolvimento de capacidades coletivas valiosas que poderiam contribuir para a aprendizagem em um contexto interorganizacional (LANE; LUBTAKIN, 1998). Neste sentido, a transferência do conhecimento tácito também se faz necessária, de modo a proporcionar a oportunidade de que ocorra a aprendizagem entre as organizações parceiras, estimulando a cooperação e o desenvolvimento de um processo inovador.

Ao analisar o processo de aprendizagem entre as empresas integrantes da Rede Merca I, segundo a perspectiva do modelo evolutivo de aprendizagem recíproca, proposto por Lubatkin, Florin e Lane (2001), foi constatado que a aprendizagem interorganizacional ocorre, predominantemente, através da interdependência de recursos e objetivos. E isto evidencia o fato de que a rede analisada ainda se encontra no primeiro estágio evolutivo de aprendizagem, denominado convergência. Na fase atual em que se encontra a Rede Merca I, as tarefas estão sendo realizadas de modo individual, uma vez que não foi identificada uma interdependência entre as mesmas, talvez pela inexistência de rotinas institucionalizadas pela rede e pela falta de um planejamento estratégico. Neste sentido, e com base nos resultados encontrados, a conclusão é que as empresas inseridas na rede analisada estão desenvolvendo esforços para "aprender a aprender" e para "aprender a confiar" (LUBATKIN, FLORIN e LANE, 2001) nos parceiros envolvidos. E, nesta fase, ainda não foi identificado um avanço significativo para o estágio de divergência, que é caracterizado pela aprendizagem através da especialização, e nem para o estágio de re-orientação, cuja aprendizagem pode ser incrementada através da co-descoberta e inovação.

Lubatkin, Florin e Lane (2001) acreditam que o modelo proposto não é linear e que a seqüência de um estágio para outro é um processo co-evolutivo interativo. No entanto, também pode ser destacado que a evolução de um ciclo para outro pode ser interrompido, caso ocorra falta de transparência e receptividade em relação ao conhecimento que está sendo descoberto, ou através de comportamentos oportunistas por parte das organizações. Isto ocorre quando as organizações tentam absorver o máximo de conhecimento através do parceiro (alta receptividade) e compartilham o mínimo possível (baixa transparência) em termos de conhecimentos. Retomando-se os resultados apresentados na seção 4.1, foi verificado que a maioria das organizações pertencentes à Rede Merca I revelaram ser receptivas para absorver o conhecimento, porém manifestaram uma baixa ou moderada transparência para compartilhá-lo. Estes resultados merecem apreciação, pois podem inibir a capacidade das organizações para co-aprenderem e inovarem conjuntamente. 
O processo de aprendizagem em redes horizontais do elo varejista do agronegócio: uma análise sob a perspectiva das estratégias, dos métodos e dos estágios evolutivos

\section{$5 \quad$ Análise Individualizada da Rede Merca II}

A Rede Merca II constitui-se, atualmente, de dezessete empresas do ramo de supermercados gaúchos do interior do Estado do Rio Grande do Sul, e sua atuação abrange dez cidades gaúchas. A Rede Merca II foi fundada no ano de 2003. No entanto, por não apresentar bons resultados, no ano de 2005 passou a aderir ao Programa Redes de Cooperação do Estado do Rio Grande do Sul. Segundo análise documental e informações constantes no material de apresentação da Rede Merca II, a Assembléia Geral, Ordinária ou Extraordinária é composta pelos Associados Fundadores e Admitidos, quites de suas obrigações e no pleno gozo de seus direitos. A Assembléia é o órgão supremo da rede, e é responsável por todas e quaisquer decisões de interesse da rede.

A Direção da Rede, segundo consta no material de apresentação da Rede Merca II, é exercida por uma Diretoria, um Conselho de Administração, um Conselho Fiscal e um Conselho de Ética, cujos membros desempenharão suas funções gratuitamente e com duração do mandato de dois anos. A Diretoria é encarregada de administrar a Rede, e é constituída de um Presidente, um vice-presidente, um secretário e um tesoureiro, todos representantes legais das associadas fundadoras e admitidas. A Diretoria se reune uma vez por mês, obrigatoriamente. Também, quando houver necessidade, se reunirá extraordinariamente, por convocação do Presidente da Rede. Vale acrescentar que, para quaisquer deliberações, o quorum será de metade mais um dos Diretores presentes (MATERIAL DE APRESENTAÇÃO DA REDE, 2006).

De acordo com o material de apresentação da Rede Merca II que foi disponibilizado aos pesquisadores, as competências de cada unidade que compõe a estrutura da rede analisada, de forma sucinta, estão definidas do seguinte modo. Ao Conselho de Administração compete apreciar e aprovar o orçamento anual da rede, assim como emitir pareceres, assessorar os demais órgãos de direção, estabelecer parcerias com fornecedores, entre outras atividades. A apreciação das contas, balancetes e outros documentos demonstrativos mensais, assim como o balanço geral e o relatório anual da Diretoria ficam a cargo do Conselho Fiscal. As competências do Conselho de Ética referem-se a plena implementação do Estatuto, do Código de Ética e do Regulamento Interno no âmbito de todas as organizações associadas à Rede ((MATERIAL DE APRESENTAÇÃO DA REDE, 2006, p.5).

A Rede Merca II elaborou seu planejamento estratégico, que norteará suas decisões e ações organizacionais. Para implementá-lo, a rede definiu quatro equipes de trabalho denominadas - equipe de negociação, equipe de expansão, equipe de inovação e equipe de 
marketing - que serão assessoradas por um coordenador externo do Programa Redes de Cooperação do Governo do Estado, que é o responsável por acompanhar o desenvolvimento da rede. Cada uma das equipes tem atribuições a desenvolver que estão contempladas no planejamento estratégico da rede (MATERIAL DE APRESENTAÇÃO DA REDE, 2006).

Segundo entrevistas com os responsáveis pelas equipes e de acordo com a análise documental, várias iniciativas já vêm sendo desenvolvidas, tais como: parcerias junto aos fornecedores, compras conjuntas, intermediação com fornecedores e acompanhamento do atendimento aos integrantes da rede, realização de propagandas em rádios, TVs e encartes, padronização dos uniformes, criação de um "símbolo-mascote" para fixar a imagem da rede junto ao público infantil, e atualização da logomarca da Rede. Sendo consideradas conjuntamente as dezessete empresas, foi verificado que as mesmas empregam em torno de 100 (cem) pessoas.

\subsection{Estratégias de Aprendizagem Interorganizacional adotadas pelas Organizações inseridas na Rede Merca II}

Ao analisar o comportamento estratégico adotado pelas organizações que integram a Rede Merca II em relação à dimensão receptividade, constatou-se que somente duas empresas revelaram apresentar baixa receptividade para absorver o conhecimento que está sendo compartilhado. Em relação às receptividades alta e moderada houve um equilíbrio entre as respostas, pois sete empresas revelaram ser altamente receptivas na absorção do conhecimento, assim como outras sete empresas manifestaram ser moderadamente receptivas.

Quanto à dimensão da transparência, foi verificado que somente três empresas revelaram adotar um comportamento estratégico de baixa transparência na descoberta e compartilhamento do conhecimento entre as empresas parceiras. E também foi observado que quatro das empresas apresentam moderada transparência nas relações de cooperação, e outras nove empresas revelaram adotar uma estratégia de alta transparência, em relação à aprendizagem conjunta. De modo geral, os resultados encontrados sinalizam que as empresas integrantes da Rede Merca II estão abertas para descobrir e compartilhar conhecimento entre as empresas (transparência), e que elas também estão desenvolvendo esforços para aumentar os níveis de receptividade em relação aos conhecimentos que são descobertos e compartilhados. Assim, baseados na receptividade e na transparência das organizações, é apresentada a Figura 06, na qual estão representados os comportamentos estratégicos individuais para a aprendizagem interorganizacional adotados pelas empresas integrantes da Rede Merca II. 
O processo de aprendizagem em redes horizontais do elo varejista do agronegócio: uma análise sob a perspectiva das estratégias, dos métodos e dos estágios evolutivos

Uma análise do conjunto de empresas participantes da Rede Merca II permitiu a construção de um entendimento de que a maioria das empresas está desenvolvendo esforços integrativos em relação à aprendizagem. E isto se revela através de alta e moderada transparências para cooperar na descoberta e na troca de conhecimentos e, também, alta e moderada receptividades para absorver o conhecimento descoberto.

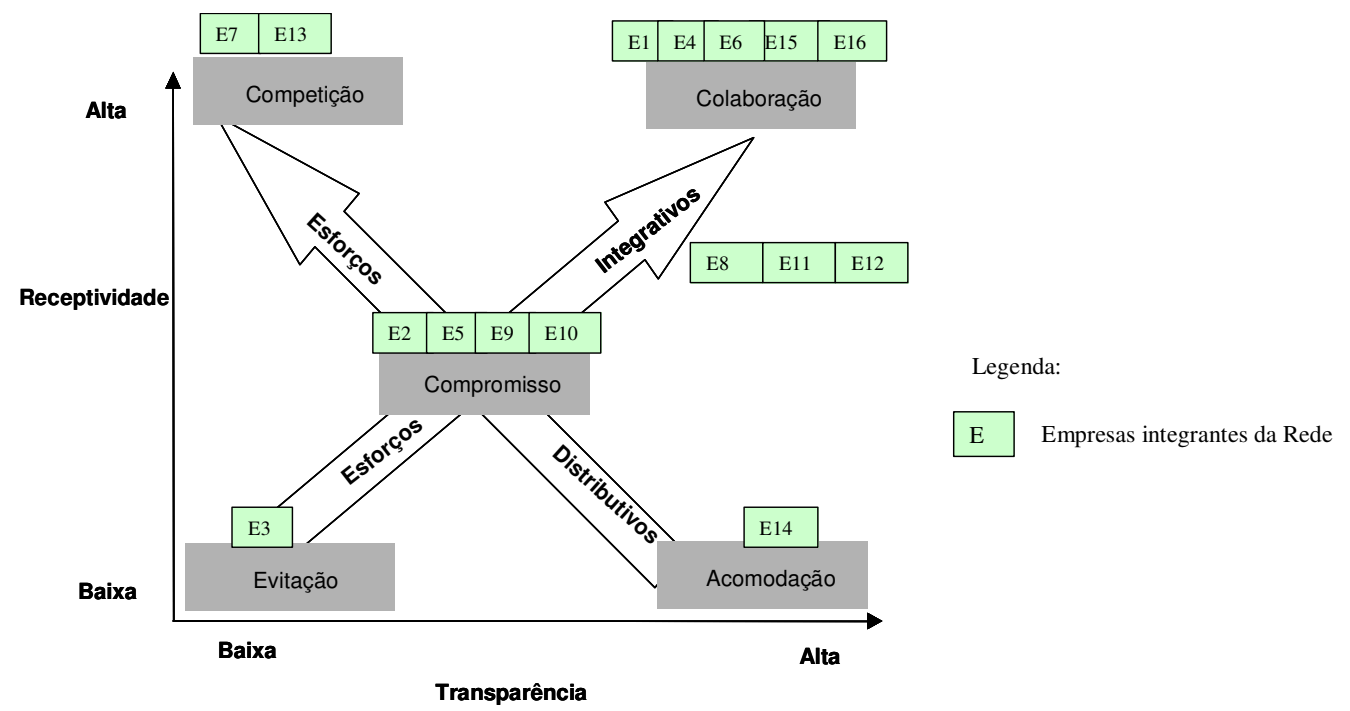

Figura 06- Estratégias Aprendizagem Interorganizacional adotadas pelas Empresas da Rede Merca II Fonte: Adaptado de Larsson et al. (1998), de acordo com os dados da pesquisa.

Ao utilizar o modelo proposto por Larsson et al. (1998) em redes interorganizacionais horizontais, que é o foco de investigação deste estudo, constatou-se que há uma concentração de três tipos de comportamentos estratégicos adotados pelas empresas analisadas: estratégias de colaboração, estratégias de compromisso e estratégias de compromisso em direção à colaboração. Estes tipos de comportamentos estratégicos podem auxiliar na aprendizagem conjunta, visto que, segundo Larsson et al. (1998) organizações com comportamentos voltados à colaboração são, provavelmente, mais hábeis e dispostas para capacitar os parceiros que adotam estratégias de acomodação e evitação. Assim, elas serão mais capazes de aumentar a sua receptividade para absorver o conhecimento gerado e compartilhado (LARSSON et al., 1998).

Pelos resultados apresentados na Figura 05, pode ser observado que duas das empresas revelaram adotar a estratégia de competição em relação à aprendizagem interorganizacional. Este é um dado que merece destaque, pois estas empresas são altamente receptivas em relação ao conhecimento, e, no entanto, não estão sendo transparentes nas relações de cooperação estabelecidas entre as empresas. Para Larsson et al. (1998), as estratégias de aprendizagem 
competitivas podem maximizar a apropriação individual de conhecimentos, enfraquecendo os resultados da aprendizagem conjunta entre os atores envolvidos.

Ressalta-se, ainda, que uma empresa pertencente à Rede Merca II está adotando o comportamento estratégico de evitação, que se caracteriza pela baixa transparência e baixa receptividade em relação à aprendizagem. Este tipo de comportamento estratégico deve ser observado pelas demais empresas, pois pode representar uma barreira à aprendizagem interorganizacional, na medida em que pode prejudicar o fortalecimento da confiança entre os envolvidos. Também deve ser acrescentado que uma das empresas integrantes da Rede analisada tem adotado a estratégica de acomodação em relação à aprendizagem interorganizacional, o que se traduz através de alta transparência e baixa receptividade. Este é um tipo de comportamento estratégico que merece ser acompanhado, pois pode representar um espaço para a adoção de comportamentos individualistas e oportunistas por parte desta empresa. De modo geral, a tendência que mais se observou nas organizações que compõem a rede em estudo é a da predominância de comportamentos estratégicos de colaboração, de compromisso e de compromisso em direção à colaboração. Esta tendência tem se revelado através de alta e moderada transparência e de alta e moderada receptividade, representando um indicativo favorável para que ocorra a aprendizagem interorganizacional e para o fortalecimento da confiança entre as empresas parceiras.

\subsection{Métodos e Estágios Evolutivos de Aprendizagem Interorganizacional na Rede Merca II}

Analisando os métodos de aprendizagem e os tipos de conhecimento que são compartilhados na Rede Merca II, foi constatado que os dois tipos de conhecimento, explícito e tácito, circulam nos relacionamentos entre as empresas. Através das entrevistas com os gestores, foi percebida a ênfase colocada por estes em relação ao conhecimento tácito, visto que os gestores foram unânimes ao afirmar a importância deste tipo de conhecimento para a efetividade do processo de aprendizagem interorganizacional.

Sabe-se que um dos grandes desafios que as organizações enfrentam se refere ao compartilhamento do conhecimento tácito, pelo fato de o mesmo residir na mente das pessoas, e de ser de difícil formalização (NONAKA e TAKEUCHI, 1997). No entanto, neste estudo, foi detectado que a realização de reuniões periódicas, bem como as práticas informais de interações entre as empresas integrantes da Rede Merca II geram alguns espaços, os quais abrem oportunidades para que os parceiros possam socializar o conhecimento tácito que existe, individualmente e nas organizações. Estes resultados servem para corroborar a 
O processo de aprendizagem em redes horizontais do elo varejista do agronegócio: uma análise sob a perspectiva das estratégias, dos métodos e dos estágios evolutivos concepção de Balestrin (2005) ao postular que as situações de interações permitem a socialização do conhecimento tácito que são elementos fundamentais para a criação de um ambiente onde possam emergir novas idéias e inovações.

Um dos aspectos que pode estar contribuindo para o processo de aprendizagem entre as empresas participantes da rede investigada, facilitando o fluxo dos conhecimentos tácito e explícito, pode estar relacionado com a presença de um coordenador externo e com a utilização da metodologia proposta pelo Programa Redes de Cooperação, desenvolvido pelo Governo do Estado do Rio Grande do Sul. Este elemento externo pode propiciar o fortalecimento da confiança e impulsionar a busca por uma maior qualificação por parte dos gestores que integram a rede. Quanto à forma pela qual os gestores se apropriam dos conhecimentos já existentes e dos novos conhecimentos que são descobertos através das relações entre as empresas, os entrevistados apresentaram os seguintes aspectos: diálogos entre os parceiros, explicitação das experiências vivenciadas por cada integrante; conversas informais; participação em palestras; benchmarking; realização de cursos de capacitação; interações entre as empresas; participação mais intensa nas reuniões; visitas às empresas do mesmo setor e a outras redes; cursos oferecidos pelas universidades; troca de idéias; e contato com os outros gestores das demais empresas da rede.

Com base nestas constatações, pode-se afirmar que as organizações inseridas na Rede Merca II aprendem através do método denominado de aprendizagem interativa. Neste método, de acordo com o Lane e Lubatkin (1998) o compartilhamento dos conhecimentos tácito e explícito pode permitir às empresas uma maior agregação de valor, ao adicionar valores únicos às suas próprias capacidades. Através desta forma de aprendizagem, as organizações podem desenvolver uma maior capacidade para reconhecer, assimilar e internalizar novos conhecimentos externos.

Ao serem questionados sobre as iniciativas que ainda podem ser desenvolvidas pelas empresas que integram a rede, visando que a aprendizagem realmente ocorra e atinja todas as organizações, evitando que algumas aprendam e outras simplesmente copiem, os gestores sugeriram: intensificar a oferta de cursos e palestras; oferecer cursos de capacitação gerencial; inovar e realizar treinamentos com pessoas externas à rede; realizar encontros informais; estimular a adesão às novas idéias; elaborar e distribuir informativos mensais sobre as mudanças ocorridas e com informações sobre a rede e sobre o mercado; utilização da Internet, realização de visitas às empresas e às cidades nas quais as empresas estão inseridas.

Ao analisar o processo de aprendizagem entre as empresas participantes da Rede Merca II, tendo-se por base o modelo evolutivo de aprendizagem recíproca, desenvolvido por 


\section{Vânia de Fátima Barros Estivalete, Eugênio Ávila Pedrozo \& Heron Sérgio Moreira Begnis}

Lubatkin, Florin e Lane (2001), foi detectado que os entrevistados valorizam a interdependência de recursos, objetivos e tarefas nas interações entre as empresas. E este fato evidenciou que a rede analisada encontra-se em um processo evolutivo para o estágio de reorientação. A evolução para o estágio de re-orientação, segundo estes mesmos autores se traduz através do fortalecimento da confiança entre os envolvidos, em um processo de descobertas comuns e da interdependência de recursos, objetivos e tarefas. Pelos resultados da pesquisa, foi possível constatar a existência de várias iniciativas, que vêm sendo desenvolvidas pela rede. Estas iniciativas reforçam a interdependência de recursos, objetivos e tarefas entre as empresas, tais como: fortalecimento da imagem da rede na região; a realização de tarefas conjuntas entre as empresas e as equipes de marketing; negociação, inovação e expansão; alteração das fachadas das lojas; criação do novo "logo" da rede; criação e lançamento de um "símbolo-mascote", para fixar a marca da rede, principalmente, no público infantil; busca de novos fornecedores; criação de uniformes padronizados; modificações no lay-out das lojas; planejamento de cenários, discutindo novos objetivos, os recursos necessários e a realização de tarefas que podem ser implementadas para o alcance dos objetivos propostos.

Com base na opinião dos entrevistados, ficou evidente que os gestores consideram a confiança e a cooperação como essenciais para o processo evolutivo da rede e para a manutenção e fortalecimento dos relacionamentos entre as empresas. Outro fator que deve ser mencionado, e que também pode ter contribuído, durante este processo evolutivo, para o estágio de re-orientação, se refere à alta receptividade e à alta transparência, por parte de algumas empresas, em relação ao conhecimento que está sendo compartilhado e descoberto na rede investigada. Assim, os resultados encontrados revelam a existência de espaços e de um clima propício para que a aprendizagem entre as organizações efetivamente ocorra, de modo a fortalecer os laços entre os parceiros e a manutenção dos relacionamentos.

\section{Considerações Finais}

Frente aos objetivos e aos questionamentos propostos inicialmente, os resultados encontrados permitiram inferir que existe diferença entre as estratégias individuais de aprendizagem interorganizacional, os métodos e os estágios evolutivos de aprendizagem adotados pelas empresas pertencentes às duas redes estudadas em função das iniciativas para formação das redes, como pode ser visualizado na Figura 076. Nas empresas integrantes da Rede Merca I (em que não há a presença de um coordenador externo) foi constatada uma predominância de comportamentos estratégicos que variam desde a estratégia de 
O processo de aprendizagem em redes horizontais do elo varejista do agronegócio: uma análise sob a perspectiva das estratégias, dos métodos e dos estágios evolutivos compromisso até a da competição. Esta tendência sinaliza para uma transferência limitada em termos de conhecimento compartilhado entre as organizações. Tal limitação no compartilhamento requer uma análise mais atenta para os motivos que restringem os graus de transparência e de receptividade por parte das empresas que estabelecem relações de parceria. Foi também constatada, por parte das empresas que integram a Rede Merca I, uma tendência para adoção de comportamentos estratégicos de evitação, com baixa transparência e receptividade para compartilhar e absorver conhecimento.

Nas organizações participantes da Rede Merca II, foi verificada uma tendência para o estabelecimento de comportamentos estratégicos voltados à colaboração, representando um indicativo favorável para a aprendizagem interorganizacional e para o fortalecimento da confiança entre as empresas parceiras. Estas constatações permitem identificar que, na Rede Merca I, há uma tendência de competição entre os parceiros. De modo semelhante, na Rede Merca II, pôde ser observado um nível de colaboração mais intenso entre as empresas. Ao se analisar o processo da aprendizagem interorganizacional, os resultados permitiram reforçar o entendimento de que o tipo de comportamento estratégico adotado é de fundamental importância, haja vista a necessidade de criação de espaços e de um clima propício ao processo de aprendizagem.

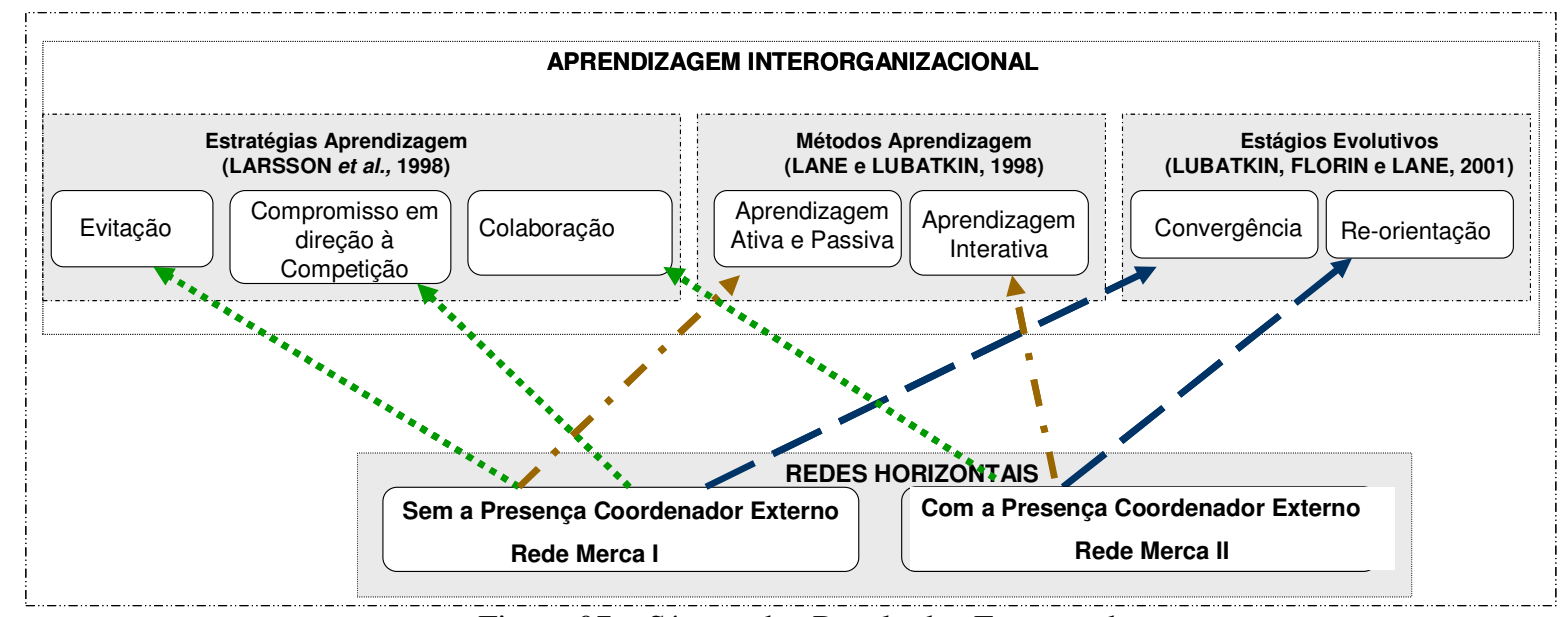

Figura 07 - Síntese dos Resultados Encontrados

Fonte: elaborado pelos autores com base nos dados da pesquisa

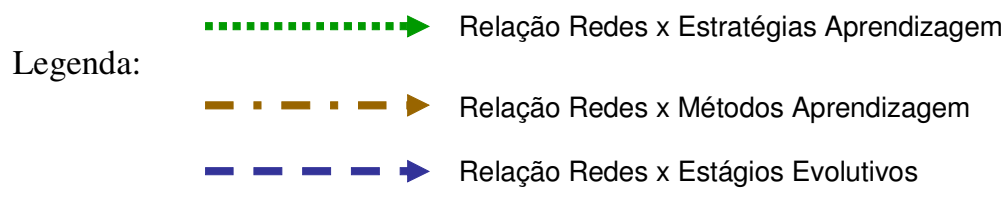

Quanto aos métodos empregados e aos estágios evolutivos em que as redes se encontram, foi detectado que os mesmos diferem entre as duas redes analisadas. A Rede 
Merca I pode ser caracterizada pelo método ativo e passivo de aprendizagem, enquanto a Rede Merca II pode ser identificada como adotando o método interativo. Estas constatações representam um indicativo de que a construção de um maior nível de confiança entre os atores envolvidos na Rede Merca I pode ser um elemento que possibilite a co-evolução para os estágios posteriores deste processo, na medida em que pode aumentar o compromisso das organizações que a integram com os relacionamentos estabelecidos sob a óptica da cooperação e, conseqüentemente, com o processo de aprendizagem interorganizacional.

Sob a perspectiva do modelo evolutivo, as evidências empíricas demonstraram que a Rede Merca I se encontra no estágio de convergência, enquanto que a Rede Merca II já evoluiu para o estágio de re-orientação. Partindo-se destas constatações, chegou-se à conclusão de que o avanço para o estágio evolutivo de re-orientação na Rede Merca II advêm da presença do espírito colaborativo e das relações de confiança existentes entre as empresas. Este ambiente favorável ao processo de evolução pode ser decorrente da participação de um coordenador externo à rede e da existência de um planejamento conjunto das ações e atitudes a serem desenvolvidas. A adoção de comportamentos estratégicos voltados à colaboração, pelas empresas que integram a Rede Merca II, pode ter contribuído para a aprendizagem, através do método denominado interativo, e também pode ter auxiliado a criação de um ambiente onde o conhecimento explícito e tácito possam circular.

As abordagens teóricas que serviram como fundamentos para o desenvolvimento da presente pesquisa, juntamente com as constatações empíricas encontradas trouxeram contribuições relevantes, principalmente, ao ampliar esta discussão para o contexto de relacionamentos interorganizacionais horizontais na forma de redes. Um fator adicional para destacar esta relevância está em que este estudo possibilita um melhor entendimento da dinâmica que envolve os elementos que fazem parte do processo de aprendizagem interorganizacional, inclusive do ponto de vista da formulação de estratégias que possam garantir a manutenção e o fortalecimento dos relacionamentos ao longo do tempo.

Além disto, este estudo também pode contribuir, de modo significativo, para o processo de tomada de decisões, por parte dos gestores, uma vez que no atual ambiente de negócios as ações e decisões tendem a ser coletivas e não mais individuais, como em décadas passadas. A realização desta pesquisa abre oportunidades interessantes para o auxílio do desenvolvimento de competências gerenciais, à luz da aprendizagem interorganizacional, preparando os gestores para conviver com o diferente, com a diversidade de idéias que as atividades relacionais proporcionam. 
O processo de aprendizagem em redes horizontais do elo varejista do agronegócio: uma análise sob a perspectiva das estratégias, dos métodos e dos estágios evolutivos

A delimitação do escopo da presente pesquisa limitou-se a duas redes interorganizacionais horizontais do ramo de supermercados o que caracteriza uma das limitações do presente estudo. Outra limitação existente deve-se ao fato de que o método de múltiplos casos, escolhido para esta pesquisa, não possibilita que sejam feitas generalizações, ou seja, os resultados e as conclusões obtidas se restringem a realidade estudada.

\section{REFERÊNCIAS}

AMATO NETO, J. A. Redes de Cooperação Produtiva e Clusters Regionais: oportunidades para as pequenas e médias empresas. São Paulo: Atlas, 2000.

ANTONELlO, C. Alternativas de Articulação entre Programas de Formação Gerencial e as Práticas de Trabalho: uma contribuição no desenvolvimento de competências. 2004. 378 f. Tese (Doutorado em Administração), PPGA/UFRGS, Porto Alegre, 2004.

BAlestrin, A. A Dinâmica da Complementaridade de Conhecimentos no Contexto das Redes Interorganizacionais. 2005. 212 f. Tese (Doutorado em Administração), PPGA/UFRGS, Porto Alegre, 2005.

CABRAL, C. de A. Histórias de Aprendizagem: Um estudo de Caso no Setor de Telecomunicações. 2001. 310 f. Tese (Doutorado em Administração), PPGA/UFMG, Belo Horizonte, 2001.

COHEN, W.; LEVINTHAL, D. A. Absorptive Capacity: A New Perspective On Learning And Innovation. Administrative Science Quarterly, v. 35, n. 1, p. 128-152, 1990.

DYER, J. H.; SINGH, H. The Relational View: Cooperative Strategy and Sources of Interorganizational Competitive Advantage. Academy of Management Review, v. 23, n. 4, p. 660-679, 1998.

ESTIVALETE, V.F.B; PEDROZO, E.A.; BEGNIS, H.S.M. Em Busca da Ação Coletiva: Estratégias de Aprendizagem Interorganizacional adotadas pelas Organizações que estabelecem Relacionamentos Horizontais em Redes. In: ENCONTRO NACIONAL DOS PROGRAMAS DE PÓS-GRADUAÇÃO EM ADMINISTRAÇÃO, 30., 2006, Salvador. Anais... Salvador: ANPAD, 2006.

FERNANDES, C. B., Aprendizagem Organizacional como um Processo para Alavancar o Conhecimentos nas Organizações. In: ANGELONI, M. T. (Coord.). Organizações do Conhecimento. São Paulo: Saraiva, 2002. 
Vânia de Fátima Barros Estivalete, Eugênio Ávila Pedrozo \& Heron Sérgio Moreira Begnis

GIL, A.C. Métodos e Técnicas de Pesquisa Social. São Paulo: Atlas, 1999.

HAMEL, G. Competition for Competence and Interpartner Learning Within International Strategic Alliances. Strategic Management Journal, v. 12, p. 83-103, 1991.

HUANG, Y.; CHU, W. Enhancement of Product Development Capabilities of OEM Supplier: Inter - and Intra-organisational Leaning. Journal of Business \& Industrial Marketing, vol. 25, no 2, p. 147-158, 2010.

KARAWEJCZYK, T. C. A Articulação entre Mudança e Aprendizagem Organizacional em uma Instituição de Ensino Superior. 2005. 334 f. Tese (Doutorado em Administração), PPGA/UFRGS, Porto Alegre, 2005.

KNIGHT, L. Network Learning: Exploring Learning by Interorganizational Networks. Human Relations, New York, v. 55, n. 4, p. 427-454, 2002.

LANE, P.; LUBATKIN, M. Relative Absorptive Capacity and Interorganizational Learning. Strategic Management Journal, v. 19, n. 5, p. 461-477, 1998.

LARSSON, R. et al. The Interorganizational Learning Dilemma: Collective Knowledge Development in Strategic Alliances. Organization Science, v. 9, n. 3, p. 285-305, 1998.

LOIOLA, E.; BASTOS, A. V. A Produção Acadêmica sobre Aprendizagem Organizacional no Brasil. Revista de Administração Contemporânea, v. 7, n. 3, p. 181-201, 2003.

LUBATKIN, M.; FLORIN, J.; LANE, P. Learning together and Apart: A Model of Reciprocal Interfirm Learning. Human Relations, v. 54, n. 10, p. 1353-1382, 2001.

MAlHOtRA, N. K. Pesquisa de Marketing: Uma Orientação Aplicada. Porto Alegre, Bookman, 2001.

MOHR, J. SENGUPTA, S. Managing the paradox of Inter-firm: the role of governance Mechanisms. The Journal of Business \& Industrial Marketing, v. 17, n. 4, p. 282-301, 2002.

NONAKA, I.; TAKEUCHI, H. Criação de conhecimento na empresa. Rio de Janeiro: Campus, 1997. 
O processo de aprendizagem em redes horizontais do elo varejista do agronegócio: uma análise sob a perspectiva das estratégias, dos métodos e dos estágios evolutivos

PETERS, L., JOHNSTON, W. J., PRESSEY, A. D., KENDRICK, T. Collaboration and Collective Learning: Networks as Learning Organisations. Journal of Business \& Industrial Marketing, vol. 25, nº 6, p. 478-484, 2010.

RUAS, R. Desenvolvimento de Competências Gerenciais e Contribuição da Aprendizagem Organizacional. In: FLEURY, M. T. L.; OLIVEIRA JR., M. de M. Gestão Estratégica do Conhecimento. São Paulo: Atlas, 2001.

THOMAS, K. W. Conflict and Conflict Management. In: DUNNETTE, M. (Ed.). Handbook of Industrial and Organizational Psychology. Chicago: Rand McNally, 1976.

YIN, R. Estudo de Caso: Planejamento e Métodos. Porto Alegre: Bookman, 2001. 